\title{
Comparative Study on the Rates of Production of Biogas from Organic Substrates
}

\author{
Wuraola A. Raji ${ }^{*}$, Yakubu Yerima ${ }^{1}$, P. T. Alufar ${ }^{2}$ \\ ${ }^{1}$ Chemical and Petroleum Engineering Department, Igbinedion University, Okada, Nigeria \\ ${ }^{2}$ Food Science Technology, Edo State Polytechnic, Usen, Nigeria \\ Email: *wuraraji2016@gmail.com
}

How to cite this paper: Raji, W.A., Yerima, Y. and Alufar, P.T. (2018) Comparative Study on the Rates of Production of Biogas from Organic Substrates. Energy and Power Engineering, 10, 508-517. https://doi.org/10.4236/epe.2018.1012032

Received: October 5, 2018

Accepted: December 23, 2018

Published: December 26, 2018

Copyright (c) 2018 by authors and Scientific Research Publishing Inc. This work is licensed under the Creative Commons Attribution International License (CC BY 4.0).

http://creativecommons.org/licenses/by/4.0/

(c) (i) Open Access

\begin{abstract}
Interest in renewable energy production and in reduction of the greenhouse gas emissions associated with fossil fuels has made anaerobic digestion of organic wastes an attractive option for alternate means of producing biogas (methane). In this present work, investigation was carried out on the unused energy present in cooked left-over waste rice as food waste and the amount of methane produced compared to cow dung and co-substrate used as feed stocks. The experiments were conducted batch wisely at mesophilic temperature with the varying percentage total solid (TS) and volatile solid (VS) calculated. It was observed that the volume of methane produced increased with increasing percentage total solid and percentage volatile solid during the 20 day HRT digestion period. The optimum quantity of methane gas produced was $57,306 \mathrm{ml}$ at the highest $92.1 \%$ VS and $12.1 \%$ TS from food waste (oryza sativa), followed by the co-substrate 12,190 $\mathrm{ml}$ and cow dung $9802 \mathrm{ml}$. The high nutritional content and calorific value present in kitchen food waste contributed to its overall yield within the shortest time interval which indicates a rapid rise through the exponential phase of microbial growth rate. Furthermore, the results obtained reveal that food waste especially cooked left-over rice should be considered as a viable feed stock for biogas production in an anaerobic digestion process.
\end{abstract}

\section{Keywords}

Biogas, Anaerobic Digestion, Volatile Solid, Organic Waste, Total Solid

\section{Introduction}

The increase in population and economic development has brought about an increase in the amount of waste generated and the use of energy. The conversion of organic materials into value-added product such as biogas has attracted 
enormous research interest. This can be ascribed to the rising energy demands and concerns over greenhouse gas emissions. The production of biogas from waste organic materials will serve to close demand. Biogas is a flammable gas produced from organic materials such as agricultural waste, manure, municipal solid waste and industrial effluents in an anaerobic environment to produce methane, carbon (IV) oxide and hydrogen sulphide in an anaerobic digester [1] [2].

[3] [4] [5] had established that the production of biogas from food wastes and other feed stock is usually done in an aerobic digester which involves the conversion of biodegradable material through the process of hydrolysis, acidogenesis, acetogenesis, and methanogenesis.

Foodwaste is a municipal solid waste containing organic matter with high calorific and nutritive value which serves as feedstock to microbes for biogas production [6]. Kitchen food waste (both precooked and leftover) is also a biodegradable waste discharged from various sources including food processing industries, households, and hospitality sector. The disposal and accumulation of food wastes imposes serious threats to the society like environmental pollution, health risk, and scarcity of dumping land. Aside food and land resource wastage, the carbon footprint of food waste is estimated to contribute to the greenhouse gas (GHG) emissions by accumulating approximately 3.3 billion tonnes of $\mathrm{CO}_{2}$ into the atmosphere per year [7]. The use of food waste for production of biogas is a better idea to eradicate the negative effect posed to the society.

Typical disposal methods for animal manure releases methane, ammonia, particulate matter, unpleasant odors, volatile organic compounds and a variety of other air pollutants, which can damage the environment and pose risks to animal and human health. Moreover, when manure is not properly managed it can cause severe environmental problems such as eutrophication of water bodies due to its high organic matter, nitrogen and phosphorous concentrations. According to [8], utilization of manure for biogas production is one of the most promising uses of biomass wastes because it provides a source of energy while simultaneously resolving ecological and agrochemical issues. The several benefits in the use of waste for biogas production as discussed in [1], include the production of energy resource that can be stored and used more efficiently, reduction of human and animal disease by improving sanitary conditions related to bad sanitation and polluted surface water, reduction of greenhouse gas emissions and it is a means of generating income by providing an energy source for technologies and activities such as incubators, kilns, lanterns, boilers and cooking flames that is a new resource or more cost effective than previous sources. However the valuable carbon contents in waste food could be a promising contribution to improve yield of biogas. The anaerobic fermentation of manure for biogas production provides biofuel and a digestate, rich in nitrogen and other substances used as a fertilizer supplement in a treated sludge [9]. [10] and [11] established that co-digestion of animal manure with a biodegradable waste appears as a robust process technology that can increase the biogas production by 
$80 \%-400 \%$ in biogas plants.

Several authors have worked on many substrates for biogas production such as [1] who studied biogas production from fruits and vegetables waste materials and a highest yield of $1554 \mathrm{~cm}^{3}$ was obtained from cow dung used as a control. [6] did a comparative study on natural and artificial inocula used for anaerobic digestion of Singaporean food waste, his results showed that natural inocula is better for digestion of food waste. Co-digestion of sugar waste in the form of sugar Bagasse and vegetable waste was studied by [12] reported that both sugar bagasse and vegetable waste appeared to be a suitable technology for biogas production. [13] investigates to find out optimum inoculum percentage for anaerobic treatment of food industry wastewater in ambient environmental, results revealed that biogas production was higher with $30 \%$ inoculums concentration as compared to $10 \%, 20 \%$ and $40 \%$ inoculum concentration in ambient environmental conditions.

In this study, batch trials were carried out to determine the methane yield in an anaerobic digester of some typical organicwastes (kitchen food waste and cow dung). Anaerobic co-digestion trials of these wastes were also investigated at mesophilic temperature range of $35^{\circ} \mathrm{C}-40^{\circ} \mathrm{C}$ by standard. The $\mathrm{pH}, \% \mathrm{TS}, \% \mathrm{VS}$ and flammability test were carried out to ascertain the presence of methane in the biogas produced.

\section{Methodology}

The major feedstocks for this study include the food waste (FW)such as the left-over rice (oryza sativa) and cow dung (gobar) shown in Figure 1(a). 14-litre capacity digester was fabricated for the anaerobic digestive system incorporating a gas cylinder with attached inlet and outlet PVC pipes. The system was connected to a tube and held in-place with clips. The tube served as a storage vessel for the gas generated in other to study the rate of production and to also carry out the flammability test with the use of Bunsenburner, it is depicted in Figure 2. Homogenization was achieved by mixing feed stocks with water and blending separately for effective digestion of the anaerobic microbes. The slurry was prepared in ratio 3:2. The feedstock and co-substrates were charged into separate digesters at the same time for the of purpose of monitoring biogas produced from each substrate. The hydraulic retention time (HRT) chosen was 20days but was extended to 40 days for further study of the whole process performed under mesophilic temperature.

The quantity of biogas produced was measured using water displacement technique where the outlet pipe of the digester was sent to the scrubber containing $2 \mathrm{M}$ sodium hydroxide aqueous solution $(\mathrm{NaOH})$ for absorption of contaminants. The scrubbed gas (methane) passed through a $1000 \mathrm{ml}$ measuring cylinder filled with water to the brim placed in a water bath, the inflow of the gas into the measuring cylinder get to displace the water and the methane was measured. The produced biogas was subjected to flammability test to confirm 


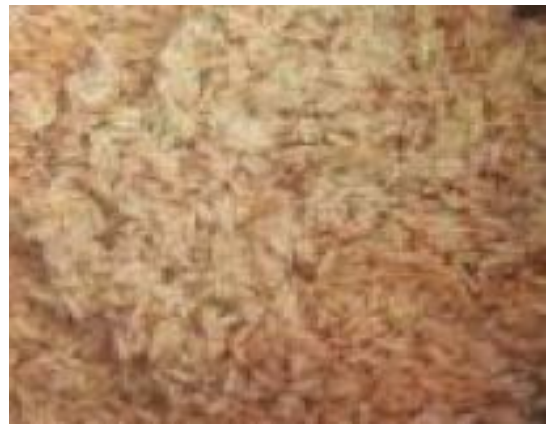

(a)

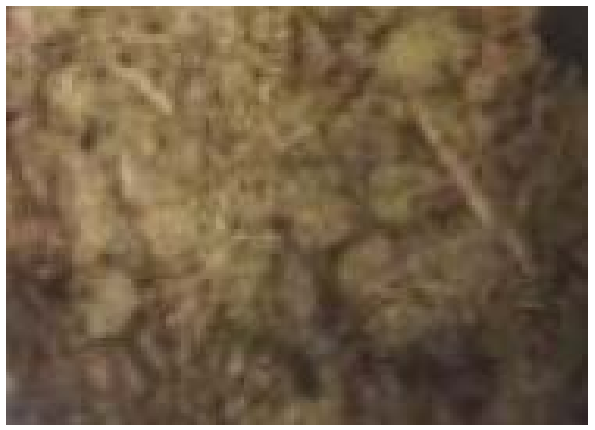

(b)

Figure 1. Substrates (a) Food waste (Oryza sativa); (b) Cow dung.

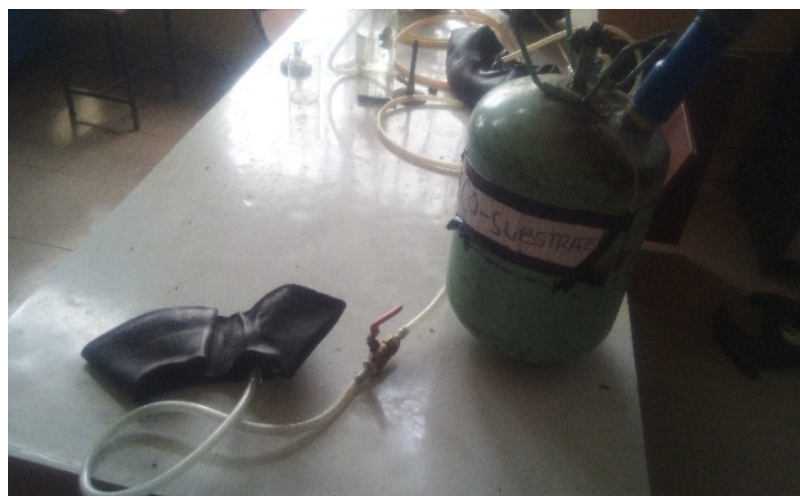

Figure 2. Experimental set-up of biogas production.

the presence of methane in the biogas produced.

\subsection{Determinaton of Total Solid (TS)}

Total Solid was measured according to APHA [14]. A $100 \mathrm{~g}$ of fresh feedstock was weighed $\left(W_{1}\right)$ in an empty crucible $\left(W_{2}\right)$ and dried in an oven maintained at $110^{\circ} \mathrm{C}$ for 24 hour $\left(W_{3}\right)$. Percentage TS was calculated by using Equation (1) as shown below.

$$
\% \mathrm{TS}=\frac{W_{3}-W_{2}}{W_{1}} \times 100
$$

\section{Determinaton of Volatile Solid (VS)}

Volatile solids refer to organic materials that are completely volatilized at higher temperature $\left(600^{\circ} \mathrm{C}\right)$ which can be measured using standard method according to American Public Health Association (APHA). A $80 \mathrm{~g}$ of oven dried sample was weighed $\left(W_{3}\right)$ in an empty evaporating dish $\left(W_{2}\right)$ heated to $600^{\circ} \mathrm{C}$ for an hour in the muffle furnace to constant weight $\left(W_{4}\right)$. Percentage volatile solid using Equation (2).

$$
\% \mathrm{VS}=\frac{W_{4}-W_{2}}{W_{3}} \times 100
$$

\section{2. pH TEST}

A sample of the substrate was placed in a beaker and the $\mathrm{pH}$ was measured using 
a $\mathrm{pH}$ meter. The $\mathrm{pH}$ measurement enables to study the effect of alkalinity or acidity on the activity of methane producing microbes.

\subsection{Flammability Test}

The biogas produced was purified using $2 \mathrm{M} \mathrm{NaOH}$ aqueous solution to scrub the biogas in other to remove unwanted gas. The biogas was tested for methane using a Bunsen burner.

\section{Results and Discussion}

\subsection{Biogas Production Analysis}

Production of biogas was evident from the second day in all the digesters which indicates the decomposition of organic matter present in feedstock, however, the measurement commenced on the third day for effective monitoring of the gas production. Figure 3 shows the biogas generated from the food waste digester. The rate of methane produced after scrubbing the biogas from the three substrates differs; food waste has the largest amount of 57.3 litres due to high volatile solid content of $92.1 \%$ whereas cow dung and co-substrate (food waste plus cow dung) produced 9.8 liters and 12.2 liters respectively. It can be inferred that digestion of food waste substrate progressed much faster than the other substrates due to the fact that food waste contains unused energy that was made available for the microbes to survive for effective digestion process. Also due to mass difference, the same volume of each feedstock does not equal the same mass as well as the amount of volatile solid per kilogram hence; variation in amount of gas generated is inevitable.

\section{2. pH Test}

The $\mathrm{pH}$ results obtained on food waste, cow dung and co-subtrate on the 10-day HRT were 2.9, 6.09 and 3.0 respectively. It is observed that the $\mathrm{pH}$ value of food waste and co-substrate was low which may be as a result of predominance of acidogenic bacteria that produces volatile fatty acids which inhibits the growth of methane producing bacteria. This implied that there was a faster rate of acidogenesis than methanogenesis during the period. The $\mathrm{pH}$ value of cow dung was found to be within the optimal range of anaerobic digestion. This is due to complete consumption of the volatile acids by the methanogenic microorganisms, thus, lowering the acidity of the system by increasing the yield of biogas.

\subsection{Flammability Test}

The flammability test was carried out at the starting period of the experiment on all the biogas produced from the batch digesters which did not burn indicating a predominance of gaseous carbon dioxide $\left(\mathrm{CO}_{2}\right)$ and other impurities that are not flammable. This shows that the methane forming bacteria were not fully active resulting to the purification of the biogas with sodium hydroxide $(\mathrm{NaOH})$ solution to attain high purified methane. Flammability of gas was observed after 


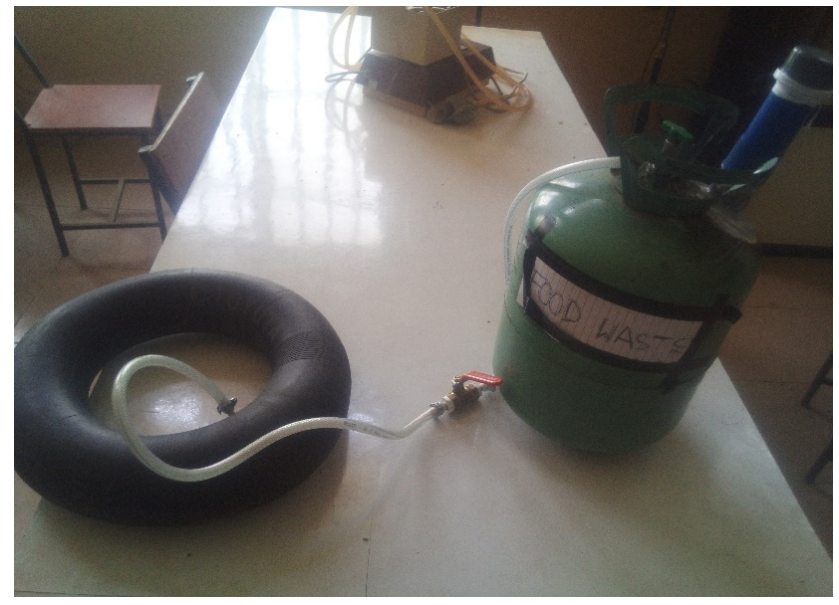

Figure 3. Generation of biogas from food waste.

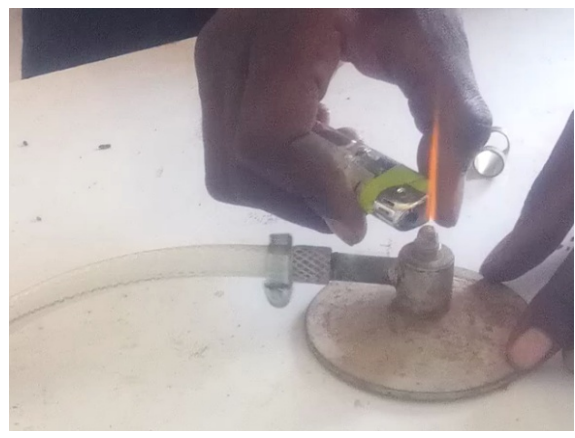

(a)

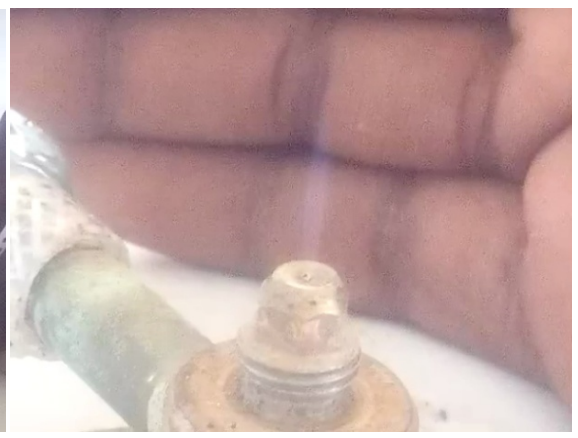

(b)

Figure 4. Flammability test set-up. (a) Propagation of the flame; (b) Complete combustion of the biogas.

purification showing a blue smokeless flame which is a characteristic of methane gas and complete combustion. Figure 4 depict the process of the flammability test carried on the biogas produced from the substrates.

\subsection{Comparative Rate Analysis of Biogas Produced from Cow Dung, Food Waste and Co-Substrate}

The yield of methane gas progresses slowly at the beginning of the process as it is shown in Figure 5(a) and rises to a maximum volume of $4575 \mathrm{ml}$ on the twelfth day but later dropped drastically to $270 \mathrm{ml}$ at end of $20^{\text {th }}$ day which maybe due to its low total solid of $9.6 \%$ and inability of the methanogens to survive in an acidic environment owning to high volatile fatty acids present. It was observed that after the 20th-day, no further biogas generation was noticed. This could be interpreted as a complete digestion within the first $20^{\text {th }}$ day indicating a shorter digestion time for cow dung. This implies that the microbial growth curve has its exponential phase recorded within 6th - 12th day followed by the decrease in microbial activity representing the death phase of the microbes. This report is in agreement to the findings of [15]. Figure 5(b) shows biogas production with cumulative of $9750 \mathrm{ml}$ at the end of 40th-day. This means that further extension 


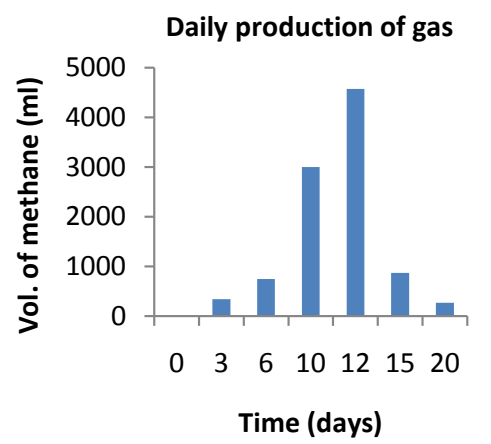

(a)

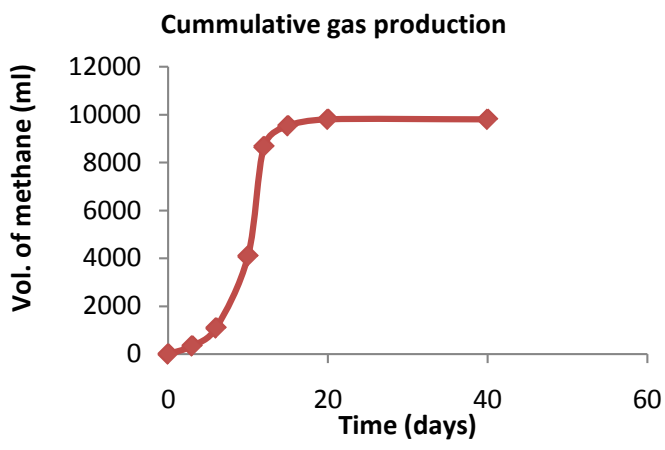

(b)

Figure 5. Graph of gas production from cow dung. (a) Daily production of gas from cow dung; (b) Cumulative gas production from cow dung.

of the HRT beyond 20 days has no effect on the biogas production.

Anaerobic digestion of food waste at mesophilic temperature and $92.1 \%$ volatile solid produced an excellent amount of methane gas of $7848 \mathrm{ml}$ on the $10^{\text {th }}$ day but declines gradually to $4800 \mathrm{ml}$ on the 20-day HRT. The food waste digester was left for several days in other to observe if more biogas could be produced. On the $40^{\text {th }}$ day, additional biogas of about $32,240 \mathrm{ml}$ was noticed. This implies that for a complete digestion to be achieved, 40-day HRT is required instead of the chosen 20-day HRT. A longer HRT tends to be suitable for the production of biogas from food waste substrate. In Figure 6(b), cumulative of 57,306 ml was produced.

The graph of methane gas produced from co-substrate (i.e. mixture of cow dung and food waste) against time is depicted in Figure 7.

The Maximum volume of methane gas produced during the chosen 20-day HRT was $3076 \mathrm{ml}$ on the $20^{\text {th }}$ day as it is seen in Figure 7(a). This rate of production is low when compared to other food waste and cow dung substrates; this is due to the longer lag period experienced by the co-substrate from the day 1 to day 12 which could be as a result of an acidic system. A pH test conducted on the $10^{\text {th }}$ day and the $\mathrm{pH}$ value was found to be 3.0 indicating an acidic environment for the microbes to survive that is caused by high activity of acidogenic bacteria which contributed to the longer lag period and a longer hydraulic retention time required achieving complete digestion. An increase in the volume of biogas was observed on the $15^{\text {th }}$ day till the $40^{\text {th }}$ day, this is shows that more gas could be produced beyond the retention time studied in this work.

Food waste has the highest rate of gas production on a daily basis with the maximum volume of $19,344 \mathrm{ml}$ on the $40^{\text {th }}$ day and a cumulative of $57,306 \mathrm{ml}$ while cow dung and co-substrate cumulative were $9802 \mathrm{ml}$ and 12,191 ml respectively as depicted in Figure 8. The unused energy and high biodegradable content of kitchen food waste contributed to its optimum yield within the shortest time interval which indicates a rapid rise through the exponential phase of microbial growth rate. In Figure 8, it was observed that HRT contributes positively to biogas production, biogas produced from food waste and co-substrate 


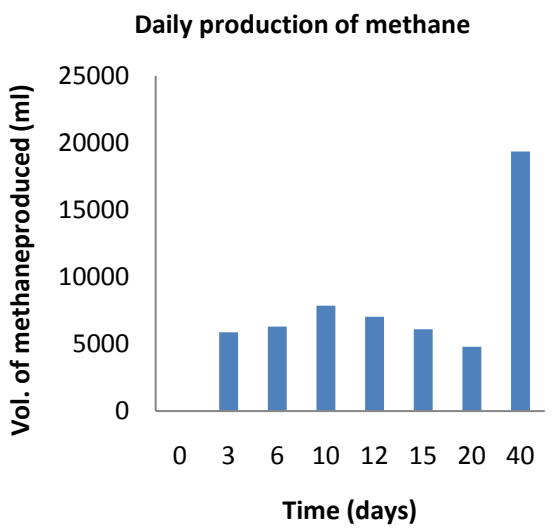

(a)

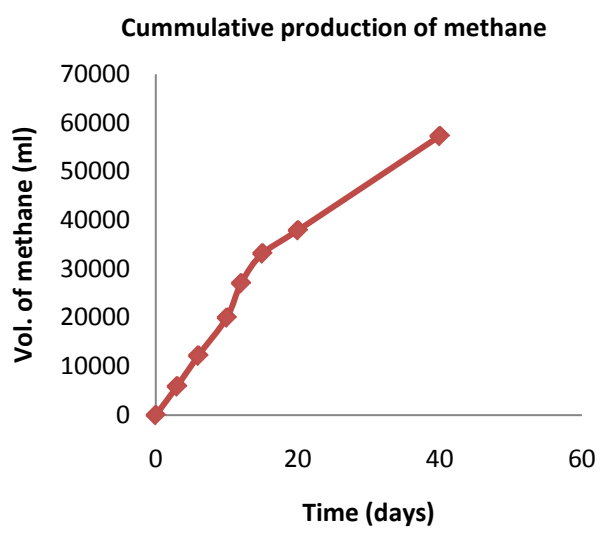

(b)

Figure 6.Gas production analysis from food waste. (a) Daily production of gas from food waste; (b) Cumulative gas production from food waste.

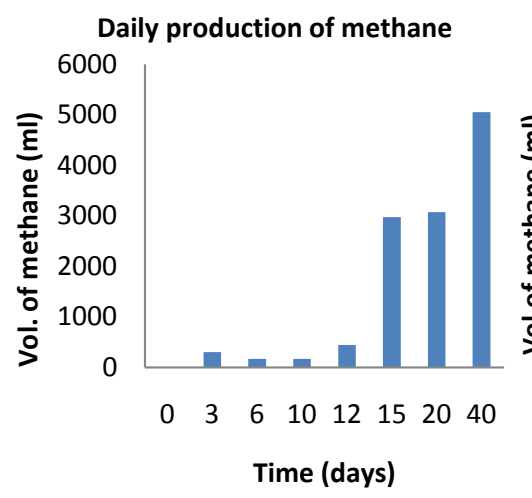

(a)

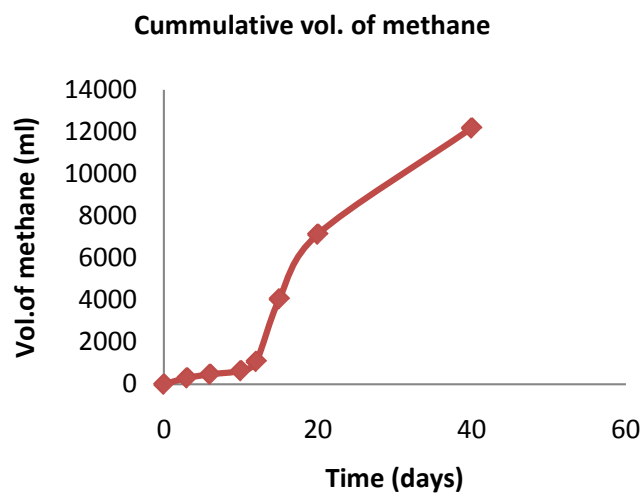

(b)

Figure 7. Gas production analysis from co-substrate. (a) Daily production of gas from co-substrate; (b) Cumulative gas production from co-substrate.

increases as the HRT increases. Thus, complete digestion was impossible within the 20-day HRT because more biodegradable organic matter may still be available in the digester for the consumption of methanogenes.

\section{Conclusion}

The yield of methane gas that was generated using food waste, cow dung and co-substrate were $57,306 \mathrm{ml}, 9802 \mathrm{ml}$ and $12,191 \mathrm{ml}$ respectively. A maximum volume of biogas produced was obtained from food waste due to its high percentage of volatile solid and total solids which contribute greatly to the performance of anaerobic digestion process. Also, the high caloric content in undigested cooked left-over rice resulted to large amount of biogas produced when compared to cow dung which had the least amount of biogas due to of its low nutritional value of digested food excreted as a waste from the animal. The biogas co-substrate production was higher than the cow dung. It is also evident from this result that the substrates used are good materials for biogas production. However, the volume produce by the same feedstock quantity is dependent on the waste material 


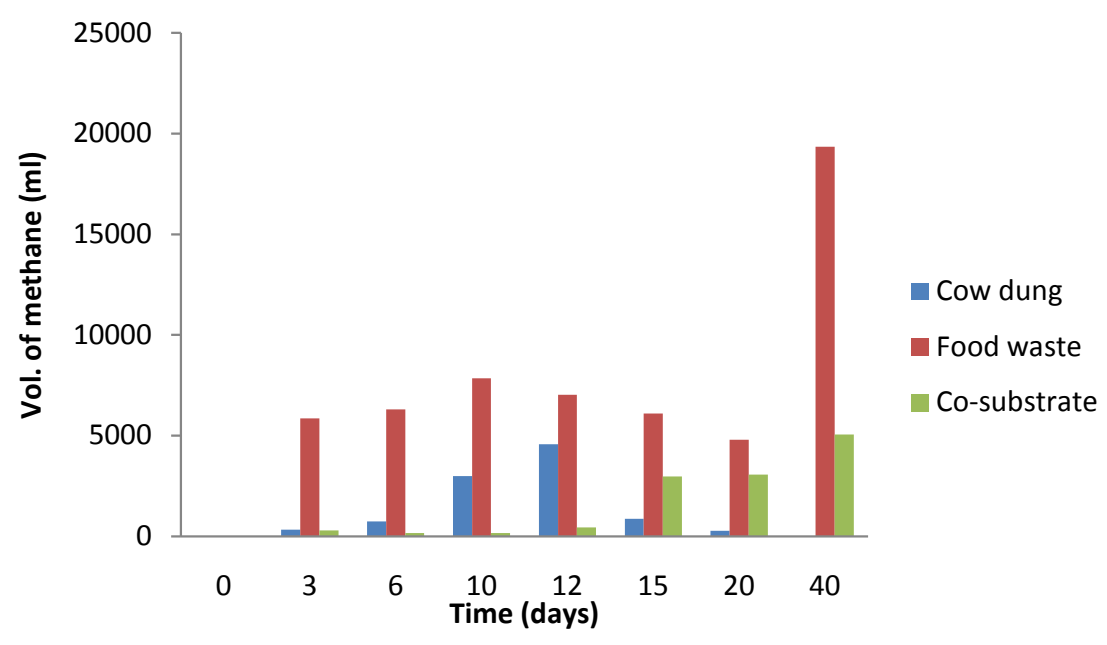

(a)

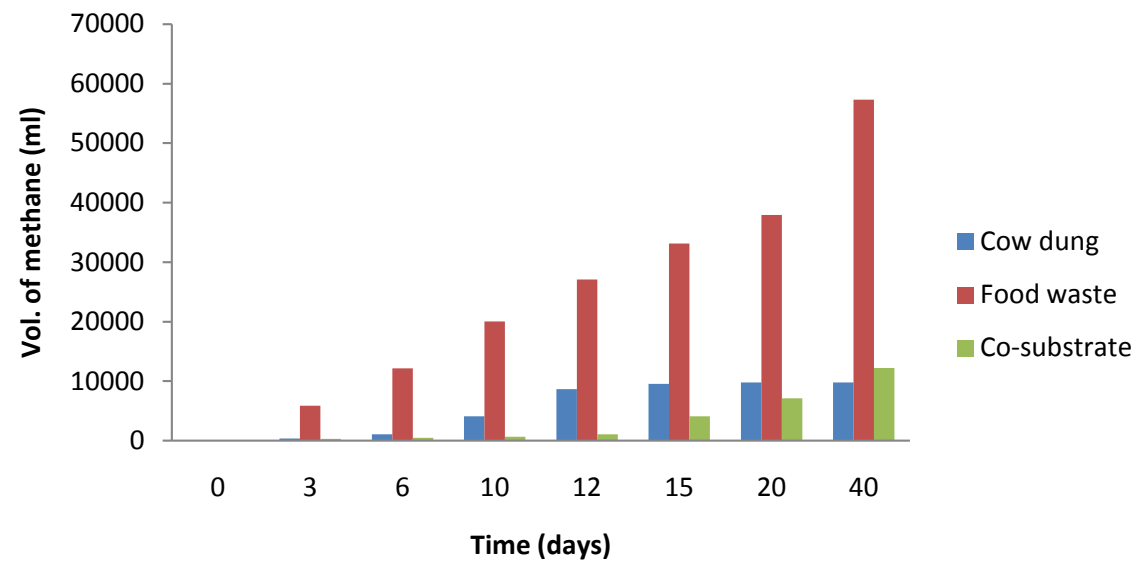

(b)

Figure 8. Comparative study of daily and cumulative production of methane gas from the substrates. (a) Daily production of methane; (b) Cumulative production of methane gas.

and hydraulic retention time. Conclusively, methane production was achieved in this study by means of anaerobic digestion.

\section{Conflicts of Interest}

The authors declare no conflicts of interest regarding the publication of this paper.

\section{References}

[1] Sagagi, B.S., Garba, B. and Usman, N.S. (2008) Studies on Biogas Production from Fruits and Vegetable Waste. Bayero Journal of Pure and Applies Sciences, 2, 115-118.

[2] Rico, C., Diego, R., Valcarce, A. and Rico, J.L. (2014) Biogas Production from Various Typical Organic Wastes Generated in the Region of Cantabria (Spain): Methane Yields and Co-Digestion Tests. Smart Grid and Renewable Energy, 5, 128-136.

[3] Pandey, P.K., Ndegwa, P.M., Soupir, M.L., Alldredge, J.R. and Pitts, M.J. (2011) Efficacies of Inocula on the Startup of Anaerobic Reactors Treating Dairy Manure under Stirred and Unstirred Conditions. Biomass AND Bioenergy, 35, 2705-2720.

[4] Kumar Vijay, K., Sridevi, V., Rani, K., Sakunthala, M. and Santosh Kumar, C. 
(2013) A Review on Production of Biogas, Fundamentals, Applications \& Its Recent Enhancing Techniques. Elixir Chemical Engineering, 57, 14073-14079.

[5] Rashed, M.B. (2014) The Effect of Temperature on the Biogas Production from Olive Pomace. University Bulletin, 3, 135-147.

[6] Jain, S., Wolf, I.T. and Wah, T.Y. (2014) Anaerobic Digestion of Food Waste Using Artificially Cultured and Natural Anaerobes under Mesophilic Conditions. Journal of Materials and Environmental Science, 5, 1709-1714.

[7] Paritosh, K., Kushwaha, S.K., Yaday, M., Pareek, N., Chawade, A. and Vivekanand (2017) Food Waste to Energy: An Overview of Sustainable Approaches for Food Waste Management and Nutrient Recycling. Biomed Research International, 2, 1-19.

[8] Budiyono, Widiasa, I.N., Johari, S. and Sunarso (2009) Influence of Inoculum Content on Performance of Anaerobic Reactors for Treating Cattle Manureusing Rumen Fluid Inoculum. International Journal of Engineering and Technology, 1, 109-116.

[9] Alvarez, R. and Lide, G. (2008) The Effect of Temperature Variation on Biomethanation at High Altitude. Bioresource Technology, 99, 7278-7284.

[10] Weiland, P. (2000) Anaerobic Waste Digestion in Germany: Status and Recent Developments. Biodegradation, 11, 415.

[11] Braun, R., Brachtl, E. and Grasmug, M. (2003) Codigestion of Proteinaceous Industrial Waste. Applied Biochemistry and Biotechnology, 109, 139-153.

[12] Keerthana, T. and Krishnaveni, A. (2016) Biogas Production from Sugarcane Bagasse in Co-Digestion with Vegetable Waste. International Journal of Latest Engineering Research and Applications (IJLERA), 1, 113-117.

[13] Pathak, J. and Srivastava, R.K. (2007) Determination of Inoculum Dose for Methane Production from Food Industry Effluent. Journal of Industrial Pollution Control, 23, 49-54.

[14] Scriban, R. Biotechnologie. 4th Edition, Tec Et Doc, 701-707.

[15] Ismail, B.S.U.I.A.N. (2012) Anaerobic Digestion of Cow Dung for Biogas Production. ARPN Journal of Engineering and Applied Sciences, 7, 169-172. 